members of the Congress opportunities to hear recognized authorities give short accounts of their own fields of work. In printed form such lectures are of more limited value and in parts read too much like potted versions of the subjects under discussion. Some interesting hypotheses and concepts concerning morphogenesis in plants are introduced by $R$. Bouillenne in "Hormones Végétales, Organogénèse, Sexualization et Floraison" and by S. J. Wellensiek in "Theoretical Backgrounds of Flowering". It is unfortunate that while presented in the form of short reviews these papers include no lists of references.

After the general lectures comes a series of symposia dealing with growth substances, fruit ripening, soilless cultura, diagnosis and control of virus diseases, mineral nutrition, uses of plastics in horticulture and heterosis and breeding of horticultural plants. Matching this range of subjects is the range of approaches adopted by the contributors. There are eritical reviews incorporating the contributor's own research findings like the papers on fruit senescence by A. C. Hulme, and on chemical control of growth and flowering by J. P. Nitsch; there are papers which are primarily experimental like those on straw. berry nutrition by $\mathrm{C}$. Bould and on foliar diagnosis of mineral deficiencies by P. Prevot and M. Ollagnicr, and there are papers which are largely descriptive like those on "Commercial Experiences in Soilless Culture" by S. R. Robins, and on "Plastics for Horticultural Use" by E. M. Emmert.

The remainder of this first volume is taken up with an impressive number of papers on vegetable crops, their culture, breeding, physiology and diseases. Here, most of the contributors present results of their own experiments, and the papers together form a valuable collection of information which, except for this publication, must have been scattered through many journals. The strong international character of the Congress is evident both in this section and in the symposia.

Although misprints can be found, the standard of production of the book is generally high, the figures and tables are very clear, and the abstracts in Fnglish, French and German which precede each contribution are a helpful feature. The table of contents would have been better placed immediately after the preface instead of after about sixty pages of information concerning the Congress; some of this might have been better in an appendix.

The delay in the publication of the proceedings of the fifteenth Congress, held in 1958, is regrettable, but regret ean be tempered with relief that they have appeared before the sixteenth International Horticultural Congress takes place in Brussels later this year.

G. P. Harris

\section{ANIMAL COLOUR AND ANIMAL COLORATION}

The Nature of Animal Colours

By H. Munro Fox and Gwynne Vevers. (Toxtbooks of Animal Biology.) Pp. vii $+246+8$ plates. (London: Sidgwick and Jackson, Ltd., 1960.) 42s. net.

$\mathrm{TN}$ view of recent discoveries and important advances in our knowledge of animal colours, especially due to the application of new and improved techniques, a comprehensive survoy of this field is both timely and welcome.
It is more usual to consider animal coloration in relation to the environment and its value to behaviour and survival, but with its reminders of the existence of internal colours and functions of pigments other than visible coloration, this book, concerned with the nature, origin and fate of the colours, provides a valuable corrective and so opens up wider perspectives.

Of the two categories of animal colour--structural and pigmentary - the former, dependent on the physical nature of the surface and the effects of interference, diffraction and light scattering, has a brief but adequate description, while the latter, dependent on chemical constitution in relation to absorption spectra, is dealt with in detail.

The various chemical groupings of the pigments are reviewed in turn, and this supplies information on their occurrence, structure, varieties and variations, physical and chemical characters and functions. These accounts are up to date, admirable in scope and detail, valuable for the many items of historical and general interest brought together and particularly useful not only for the information provided but also for indications of its limitations and even its complete absence.

Melanin is not the only dark pigment, as the accounts of protein tanning and the ommachromes show, and the latter are unique since genetical research was responsible for their recent discovery. The well-known tyrian purple related to the melanins is not concerned with coloration in animals as it appears in a secretion after it leaves the body. Carotenoids, widespread in animals and combined with proteins or dissolved in fats to give a variety of colours, are obtained in their food, since they cannot be synthesized by animals. They are related to vitamin A and visual pigments. Chlorophyll, the main plant pigment, is absent from animal tissues except for a few symbiotic algae, but derivatives from food form green pigments in a few animals.

Hæmoglobin, as abundant as melanin, is a blood pigment with its primary function respiratory, and only relatively few animals owe their surface coloration to its presence. The same applies to other blood pigments of more limited distribution and the differences in chemical structure are concerned more with their efficiency as oxygen carriers than colour. Colourless respiratory pigments do not appear to exist. Hæmoglobin is broken down to bile pigments. These bilins can colour the integument or internal organs of some invertebrates or calcareous structures such as birds' egg shells, gallstones or molluscan shells.

Apart from activity in the tanning of proteins and synthesis of melanins, quinones appear as pigments in echinoids and scale insects (cochineal), but little is known of their origin or function.

These few notes give some indication of the range and treatment of the subject and the successful blend of biochemistry and natural history. There is a vast amount of information and more than six hundred references are listed. The presentation is good with a style clear and precise which maintains and stimulates interest to the end. There are some fine illustrations on eight colour plates.

This book offers both teachor and student much in concise form, and with the final chapter on the study of pigments in the laboratory and the appendix giving a synopsis of animal colours should appeal, as the authors hope, to the sixth form at school and a wider circle from the naturalist to the research worker.
E. A. Spavi 